\title{
Authoring the Readerly Experience: On Materiality, Multimodality and Singularity of Literature in Nicola Barker's H(a)ppy
}

\author{
Tymon Adamczewski \\ Kazimierz Wielki University \\ tymon.adamczewski@ukw.edu.pl
}

Received 13 May 2021; accepted 29 September 2021; published 29 December 2021.

\begin{abstract}
This article offers an overview of typographical and experimental strategies employed in contemporary novel writing in the context of author-ing, authority, freedom and experience programming. Nicola Barker's novel H(a)ppy (2017) is discussed as an example of a rising trend in contemporary literary production characterised by an emphasis on multimodality and materiality of texts where the physicality of writing serves as a significant mode of communication, simultaneously aiming to transcend its medium. My claim is that although visually engaging and fascinating in itself, the typographical experimentation, apart from connoting a degree of liberation for both the writer and the reader, can also be looked at from the point of view of a particular "authoring," i.e. programming of reader's reception. This approach is contextualised against the backdrop of the theoretical discussion concerning the notion of author (Roland Barthes, Michel Foucault, Jacques Derrida) as well as aspects of materiality of writing and of subverting authority in postmodern fiction and visions of the reader in multimodal texts. This is followed by a reading of the novel with reference to its themes of control and typographical experimentation. The article also recognises a performative aspect of such type of writing.
\end{abstract}

Keywords: Nicola Barker; materiality; experience; experimental typography; author 


\section{Introduction}

Nicola Barker (b. 1966) is a British writer with an undeniable aptitude for experimentation. This tendency to explore fiction's limits is not only visible in constructing unconventional stories about strange characters and settings but also in employing intriguing formal and narrative solutions throughout her many books. Whether it is Wide Open (1998), which literally opens its narrative with the use of characters with the same name, or the epic-length Darkmans (2007), intricately organised and linguistically puzzling but with almost indescribable plot, Barker's fiction challenges both the writing conventions and the reader's expectations.

Although her latest novella I Am Sovereign (2019) retains the experimental spirit in deconstructing authorial agency and the notion of authorship, it is H(a)ppy (2017) where, to paraphrase Marshall McLuhan, the materiality of the written medium is the message, or at least an important part of it. Significantly, owing to its content, form and the reader's experience it produces, the novel invites considerations of varied aspects of authoring and control. The story takes place in a dystopian world of the future where the personal almost does not exist. Instead, all thoughts and feelings are communicated on an Information Stream - a news or social media-like feed, serving to record the flow of one's intellectual processes or to signify one's mood and status. When the main character, Mira A, undergoes a rebellious breakdown, the narrative is also physically transformed. Correspondingly, this is expressed through radical modifications to layout, typography, typeface and the writing's graphic design, all of which result in puzzling the readers, forced to make sense of what goes on in the story and on the page.

This accounts for some of the most daring visuals in a book of fiction. They reflect the author's interest "both in the buzzing, multiplying, uncontrollable meaning of words and the visionary realms that lie beyond them" (Jordan, 2017). While such unconventional design draws attention to the materiality of "the novel-as-object," such ostentation also manages to achieve more: it "always has a narrative purpose" (Barry, 2018). The combination of such features rightfully earned the novelist the Goldsmiths Prize for innovative fiction in 2017, on top of other awards, cementing "Barker's reputation as one of her generation's most adventurous avant-garde practitioners of experimental fiction" (Schoene, 2020, loc. 95). Her writing certainly aims to map the present. It centres on the subject of freedom of speech (and artistic expression) and can be read as a warning against "the dangers of algorithmically-driven language policing" in "a complex contemporary climate," in line with the dystopian literary tradition of George Orwell or Aldous Huxley it evokes (Darlington, 2020, p. 99). The explosive typographical poetics that reflect a rebellion against the rigid control of tradition, authority, or what the novel terms as the System, bring to mind various avant-garde and conceptual experiments in art and literature. These in many ways were intended to confront the audience with the ambiguity of art, its interplay with form and message that could imply interpretative openness or a non-authoritative response. However, the use of radical print and design tactics may also posit questions about the actual privileging of the reader's liberty in interacting with the book. Perhaps by complicating both writing and reading - instead of being a sign of semantic multiplicity or liberation from the physicality of a codex - such works still follow modes of experience design thinking or even of authorial control? 
What follows offers a look at the typographical and experimental strategies employed in Barker's novel in the context of author-ing, authority, freedom and experience programming. The book is discussed as part of a rising trend in contemporary literary production characterised by an emphasis on multimodality and materiality of texts in which the physicality of writing serves as a significant mode of communication. My claim here is that although visually engaging and fascinating in itself, the experimentation in question, apart from connoting a degree of liberation for both the writer and the reader, can also be viewed from the point of view of a particular "authoring, i.e. programming of reader's reception.

\section{Author(ity) of the Material Text}

The use of blank pages and coloured letters (or whole words), floating typeface in different fonts and sizes with sentences printed in reverse or surrounded by meticulously constructed graphic designs made up of mathematical symbols or equations - practices like these permeate Barker's book and inevitably bring to mind similarly challenging print and design procedures across literary history. Found in concrete poetry or in the works by, for example, Stéphane Mallarmé or Guillaume Apollinaire, "unusual" layout or graphic interventions may be linked further to incredibly varied past and present literary production of authors as diverse as George Herbert, with the early modern typographies of The Temple (1633), Laurence Sterne, with Tristram Shandy (1759), but also include more experimental forms, like Raymond Queneau's A Hundred Thousand Billion Poems (1961), or Mark Z. Danielewski's House of Leaves (2000), to name but a few. While such instances of visual book design may connote attempts at assigning meaning to non-verbal forms of signification in literary writing, they may also express an intentional disregard for traditional printing conventions or imply the idea of a subversive liberation from their confines. In line with much of avant-garde thinking, such practices easily suggest artistic freedom of expression, especially given the long-running lineage of formal and material explorations. These, in turn, document attempts at transgressing the written page, for example through effecting an immersive readerly experience. Although the effects of such strategies may be intellectual and immaterial, the physicality of the printed word plays an important role in writing (and in reading) fiction and needs to be discussed as well.

Certainly, writing, viewed as signs on paper, does not merely perform an expressive function of "simply" conjuring up the storyworld or of representing the state of mind of the protagonists. It is linked to questions of the authorial domination over a text and the various meanings this idea entails. Already in 1967, the now-canonical Barthesian attack on the institution of the author successfully freed readers, interpretation and critics from the yoke of biographism. It was an achievement inaugurated in many respects by Formalism and New Criticism. Yet, the positivism of these positions was counterbalanced by a thinking rooted in the combination of phenomenology, anthropology, psychoanalysis and, above all, in structuralism. Such background sprouted what Seán Burke called "an iconoclastic and far-reaching form of antisubjectivism" allowing critics to do away with uniform meanings and to promote interpretative liberty of the reader (1998, p. 14). In a similar way, the French thinker's distinction between readerly and writerly texts, although historically conditioned as a gesture of non-conformity against commodified myth-consumption, further promoted un-authorised readings and uses 
of the texts by the readers. An offshoot of such thinking may be found in Michel Foucault's consideration of the notion of author and author function, especially in his recognition that the discussions of the discursive power stemming from the texts produced by or about the author may actively influence the reading to effectively "neutralize the contradictions that are found in a series of texts" (1984, p. 111). It is in this vein that the French theories of the 1960s, explored also by other poststructuralist critics, not least by Jacques Derrida, privileged "the disappearance of the writer, the autonomy of writing, the beginning of écriture in an act of textual dispossession" (Burke, 1998, p. 4).

Although these developments opened up the understanding of the text itself and writing as a process to a multiplicity of meanings and interpretations, they did not, programmatically, regulate the questions of the reader; nor did they pay particular attention to the very materiality of the signifiers. In this context, the readerly experience could be construed as a paradoxical space of negotiation between liberty, authority and control, or a space where these forces and processes are materially manifested. Visual and typographical experimentation may thus be regarded as echoing the postmodern notion of play, providing, in a way, a literal, i.e. visual, illustration of how the signifier is affected and shaken by the meaning conveyed. These processes would often take the form of narrative strategies as illustrated by the likes of Kurt Vonnegut, William Burroughs, Donald Barthelme, or William H. Gass, whose works might serve as reflections on the rebellious literary forms directed against the authority of convention: the printing tradition, the Western custom of reading (i.e. left to right, top to bottom) or the concept of realism. By including non-verbal means of communication such works constituted a comment on the very idea of fiction writing and presented the postmodern experimentation of the twentieth century as particularly susceptible to reading through the poststructuralist lens.

Another aspect of typographical experimentation explored by many contemporary authors is the performative character of writing. It corresponds to what Roland Barthes penned already in his seminal essay on the author as a poetics of openness that is endemic to perceiving writing as an "oblique space" (1977, p. 142), no longer conceptualised as "a line of words releasing a single 'theological' meaning (the 'message' of the Author-God) but a multi-dimensional space in which a variety of writings, none of them original, blend and clash" (1977, p. 146; my emphasis). Claims like these anticipated the more recent multimodal understanding of communication, writing and typography and were eagerly spotted by critics like N. Katherine Hayles (2002) or Alison Gibbons (2012). To see printed communication and writing as multimodal is to construe them as being capable of, and often deliberately intent on, conveying information and meanings through numerous varied channels of communication (modes) to get its message across (cf. Kress and Leeuwen, 2010). The Barthesian movement from work to text, as Hayles recognises, was not only formative for seeing text as a rhizomatic network of scattered links (hypertext), co-authored by more than one person, but was also instrumental in instigating much of current research in multimodality and performative discourse analysis (2002, p. 30). However, the readerly freedom offered by multimodal texts, despite relying on a multitude of semiotic modes in the communication and progression of their narratives, may be problematic. Both theoretical positions which struggle with the concept of reception (e.g. Phenomenology, Narratology) and approaches that tackle interacting with graphic elements in literature hinge on what Glyn White identifies as "a concept of an active, determined and adaptable actual reader" who is "implied and encoded in the text but at the same time, actual 
and external to it" (qtd. in Gibbons, 2012, p. 4). That is why Gibbons assumes a twofold notion of the reader who is both envisioned by the text and who "physically engages with the book in an actualised way" (2012, p. 4). Writing in this sense indicates not a space for interpretation, but an arrangement of material traces which, through their connotations and experiences, provoke or suggest certain meanings to the reader. While much of such materially centred writing can be easily construed as attempts at subverting the rules or authority of traditional (realist) fiction, for example through the pervading strategies of parody, pastiche and experimentation at the level of the signifier typifying many postmodern literary works, a paradoxically strong authoritarian dimension may still be found underlying even the "unruly" productions. Linda Hutcheon recognises that although such works assert "their modernist autonomy as art," they also operate on a kind of contradiction that is characteristic of postmodern art in general: subverting the dominant discourses, but at the same time being "dependent upon those same discourses for [their] very physical existence" (Hutcheon, 2004, pp. 45-46). Such a claim might not only testify to the mutual interdependence of power and submission, but also signal that even the most daring experiments in writing need a regulatory context so they may enact their actual subversion. This seems to go hand in hand with Derrida's claim that "writing is unthinkable without repression" (2005, p. 285). The philosopher regards this process as one which entails erasing empty spaces on a sheet of paper or leaving physical marks (traces) on the very surface for writing, but highlights a strong material element of inscription, dependent, for example, on seeing the unconscious as "a surface exposed to external world" (Derrida, 2005, p. 266) or on the fact that "words are also and 'primarily' things" (Derrida, 2005, p. 275).

The questioning of authorial presence effected by such understanding of experimental print materiality in a book form is further problematised by the immersive character of the reading experience. Facing the reader with discordant graphic symbols or bizarre notation certainly encourages a more active participation in the production of sense and meaning than interacting with traditional print. It thus gives the impression of a heightened sensory involvement while reading, in which the visuals or non-standard format force the reader to make sense of the schizophrenic page design. Although such modes of writing can produce an emotional reader response, they may contribute to both the feeling of a direct non-mediated experience or, paradoxically, evoke an authorial presence. According to Hans Ulrich Gumbrecht, such immersive, moment-extending feeling may take the form of what he describes as "presentification" (cf. 2004) - a perception of extended temporality of a given moment. It is the result of the tactile involvement in the very materiality of the book, when the reader is forced to stray away from the conventional reading practices, for example by alterations to traditional typography. For Gumbrecht, echoing some of Baudrillard's claims about the mediated status of contemporary culture, the presentification effected by such sensory experiences fits into the materiality driven tendency of contemporary culture typified by a longing for those types of experiences which can affect multiple senses through tactile impressions (cf. 2004, pp. 94-95). Apart from contemporary experimental multimodal literature analysed, for instance, by Gibbons, such reasoning might explain the gradual turning away from virtual experiences to the various retro trends (vinyl records, boardgames, paper notebooks, etc.) associated with physical and material experiences and their growing popularity in Western culture, aptly termed by David Sax as Revenge of the Analog (2016), or manifested in what Jessica Pressman identifies as the aesthetics of bookishness (2020). 


\section{3. (Un)Authorised Reading}

In attempting to transgress the written medium and its limitations, the peculiar materiality of $H(a)$ ppy demonstrates how authoring a text is entangled in aspects of control and influence. Interestingly, while the book thematises unruly, dissenting and antiauthoritarian behaviour, Barker herself seems to approve of asserting authorial control over the text. In one of the interviews she outwardly admits to thinking about her books as items that originate primarily in a digital environment, in which they constitute "the version [...] completely controlled by me," and reveals that the transition to a physical book form causes fears of losing the power over the text: "when it goes to someone else, or it's even read by someone else, or even when it's in physical form, I find that almost disturbing" (Barker, 2018). A similar power struggle over materiality seems to inform the novel's unconventional form.

Even without the authorial guidance, however, both the themes explored in the narrative and the typographical strategies employed throughout the text centre on the notion of control, power and individual freedom. This might explain why the novel opens with an Author's Note advising a multimedia reception: "Although by no means essential, this novel is best enjoyed in conjunction with Agustin Barrios: The Complete Historical Guitar Recordings 1913-1942" (Barker, 2017, p. ii). In such a subtle way, but already from the onset, the reader is made aware of suggestions about interacting with the book. Remaining largely invisible as the story progresses, such strategies inform the overlap between reality, fiction and the testing of the limits of the written medium. The futuristic, post-apocalyptic world of the novel is a place of "The New Path" which calls up a sense of security and comfort for the protagonist, Mira A, who signals being one with the System by commencing her story in a collective voice: "We are innocent. We are Clean and Unencumbered" (Barker, 2017, p. 1). As an artist (a musician and guitarist), Mira also recounts how the past was done away with because of tight bonds of competition, plagues, death cults and all sorts of filth and corruption. In this bright world of the future, such familiar-sounding "grand narratives" were redefined as lies and replaced by The Graph - proof of

how in balance we are: as a person (our physical and mental health), as a small community (a community of skills, a community of friends, a community of consumers, a community of thought) and as a broader society - as a race, as a planet, as a galaxy. Many graphs, one Graph. (Barker, 2017, p. 3)

It quickly dawns on the narrator that this seemingly perfect world is one of total surveillance, especially when the word "happy" fails to correctly appear on the Graph and pops up in a bizarre, erroneously spelled form - with the bracketed letter a, printed in red ink - H(a)ppy.

Treated initially as a form of a glitch in the system and manifested as a typo, or an error in writing, the misspelled signifier acquires various explanations throughout the story. In this perfectly balanced world, just like all the negative words referring to the past, or ones betraying affects and stronger feelings, it may easily signal what is called in the storyworld an EOE (excess of emotion). This causes selected verbal items to light up, pinken, or to be rendered in colourful print to suggest both affective investment and subsequent graphic loss of control. The text itself explains the use of colour in psychoanalytical terms as representing the Ego (Barker, 2017, p. 19) or a means of surveillance through which - despite pronouncements of 
being clean, satisfied and in balance - being happy always comes out as impaired and not always completely possible. Instead, it is expressed in an uncertain, bracketed delivery, indicating a gap between the signifier and the signified and echoing the Orwellian doublespeak and doublethink. Writing in the book, correspondingly, becomes a form of double notation firstly, a standard, $1^{\text {st }}$-person recording of thoughts, feelings and narration, which visually illustrates how the diegetic world operates; secondly, a signifying system in which typography invites the reader to interpret the graphic elements. While within Barker's storyworld, keeping psychological balance is controlled by chemicals and pills intended to eradicate desire ("desire breeds dissatisfaction"), the complex and discordant page design becomes the means of rendering further and further transgression to the rules of the System: from occasional graphic intrusions, e.g. the literally bubbly word "fizz" (Barker, 2017, p. 126), to more elaborate structures which form wild and seemingly chaotic font mash-ups, scribbles or inexplicable constructions of symbols and colour collages. On the narrative level these typographical experiments serve to record the transition in Mira A's character from a loyal subject who "reproduces the dominant discourse about her own stable and smooth subjectivity, evacuated of any craving or lack" (Byrne, 2020, loc. 3571), to an insolent individual hesitant and full of questions about the written, material effects of her meditations, e.g. "Why is this capitalised?" (Barker, 2017, p. 33). The strategies she adopts to cheat the system (e.g. using seemingly neutral stand-in words for emotionally laden ones, which would raise suspicion) testify to the internal struggle marking the difference in the intended meaning and surface form as seen on the Graph. These allow the reader to trace the struggles against authority, but also frame the reading audience into the role of someone actually reading Mira's feed, often simply leaving it up to them to make sense of the given page design.

Bracketing and colouring of the letter "a" within the novel not only brings to mind Derrida's seminal text on difference but can be symptomatic of the need to communicate across disparate channels of signification. It illustrates how the very materiality of writing and of print might also be charged with meaning. The philosopher's initial declaration of willingness to focus on a letter ("I will speak, therefore, of a letter") constitutes part of the theoretical underpinnings of what Barker's novel aims to demonstrate (Derrida, 1982, p. 3). His text sets out to problematise the relationship between speech and writing but also conceptualises the misspelling in his neologism and the significance of the very letter as a "discreet graphic intervention" (Derrida, 1982, p. 3; my emphasis). It is thus the "graphic difference ( $a$ instead of $e$ )" that emphasises the visual dimension of an otherwise auditory phenomenon. Although Derrida highlights the fact that "this marked difference between two apparently vocal notations, between two vowels, remains purely graphic" (1982, p. 3), the very discourse he would go on to produce famously transgresses its materiality with auditory and typographical contexts, e.g. with neologisms (hauntology) or using brackets to draw attention to the instabilities of language. Rather than simply passively describe his intention to demonstrate how writing does not imitate speech, his writing is notorious for problematising its mode of expression. Eleanor Byrne, in her recent reading of Barker's novel, adds a Lacanian context to this otherwise Derridean typographic reference. She points out that the psychoanalytical musings on the theories of the subject tap into how, following Žižek, the capitalised Other might take the form of "an anonymous structure, such as language, or [...] an ideological system" often exposed in fictional dystopias through such works' probing of language and "anonymous or indifferent power structures, and 
ideological systems that regulate human subjects and their interactions" (Byrne, 2020, loc. 3611). In $H(a) p p y$, this probing rests on a reversal which is tangible in both content and form. In a world of a continual present even the "buildings are mutable. All structures - narrative, musical, architectural - must contain within them the capacity to be remade. There are no permanent edifices. Only The System. Only the Young. Only these two may remain indefinitely" (Barker, 2017, p. 33). Consequently, art, just like any form of inscription or signifying system at large, becomes dangerous to its dynamics precisely through the stability of its material permanence. In contrast to the notions of textual difference, as recognised by the likes of Derrida, Barthes and Foucault, also at play in such systems like literature, it is the very stability and its links with materiality (of the tale itself) that make artistic production function differently here. While all the structures listed above can be seen as structures in which mutability is the norm, and in which the French philosophers would be willing to recognise conflicting meanings, the novel, paradoxically, stages any forms of creative process of ascribing meaning (to objects, things or texts) as subversive and dissident because of the permanence that art provides. In this way, the text positions its readers as onlookers, assistants to the unfolding revolution manifested in typographical gimmicks, and makes them tackle the discordant page layout to successfully fill in the narrative gaps and ambiguities.

The auditory context of difference, which Derrida (1982, p. 3) states is read or written "but cannot be heard," also refers to the postmodern notion of play (Derrida, 1982, p. 7) and can be understood within the latter's musical connotations. Indeed, it is while relying on sound that Barker's novel seems to conceptualise various strategies and modes of communication to act out its interest in transgressing its medium. Both the initial suggestion to listen to Barrios' music while reading, as well as the use of various typographical alterations or graphic intrusions, might suggest an intention to convey meaning beyond the verbal domain of writing's materiality, all of which actively contributes to shaping the text's reception.

The musical and auditory contexts developed within the narrative take the form of the twisted and dissident story of the Paraguayan guitar virtuoso, Augustin Barrios (1885-1944). This New World guitarist and composer, believed to be the first classical guitarist to make recordings at all, crops up in Mira A's searches of the Sensor and the Information Stream when she goes back to historical records about music and discovers a patchwork story of colonial domination. This search also reveals a bitter and disconcerting tale of a troubled musician. Plagued with a form of inexplicable anxiety, the protagonist is haunted by melodies, sounds and images of the artist, as she tries to erect an illicit church-like structure in her mind (Barker, 2017, p. 43), modelled on Barrios' (actual) musical masterpiece La Catedral (1921). Interestingly, the opening of the book quotes an unknown critic describing the composer's recital during which his music, just like Barker's visually stunning writing, seems to be spilling out of its medium. This effect is remarkably similar to what Nicholas Royle calls "veering" and what he uses to draft a deconstructive Theory of Literature (2011). The French word "virer" (to turn), resonating with cognates that describe movement and space (revolution and environment, respectively), might also suggest aspects of immersion produced by texts stemming from the forces within them which effect a kind of push-pull dynamics characteristic of texts we become engrossed in. According to Royle, veering - both noun and verb - also corresponds to the text's frequently revolutionary potential for setting (things, the reader) in motion. The notion thus simultaneously draws attention to how an expression in a signifying system (text) 
can gesture beyond its given medium. Hence, the musician, appearing in a native costume with feathers and bamboo, surprises the audience when "The guitar becomes a piano, violin, flute, mandolin, drum. There is nothing that his man can't do on the guitar. At times it seems the guitar plays itself..." (Barker, 2017, p. iv). The choice of an early twentieth-century review of Barrios' performance might suggest a dissolution of the authorial self in an artistic process, but it can also be read as the intention to explore the idea of loosening or going beyond the necessity to rely on the medium of communication (and its vagaries) in order to arrive at an instant (perfectly understandable) communication - one where experiences are immediately understood and do not have to be negotiated. This might suggest a longing for authorial power over the meanings of one's work, especially that

Barker herself seems to be happiest driving the narrative towards in-between spaces where she can explore questions of belief, faith or the sublime, as her protagonists continue to veer toward the borders of what we might think of and recognize as text. (Byrne, 2020, loc. 3671)

The deconstructive veering at play in the novel is described and enacted on the level of content and form. A particularly understood multimodality of writing and unambiguous communication is specifically visible in the case of the explorations of the Guarani language, a tongue used by the Paraguayan natives, deemed to be the most widely spoken indigenous language in South America (Barker, 2017, p. 164). In this light, the precolonial past in the novel, echoing with issues of domination and control, also becomes linked to the idea of the clarity of meaning. As we soon learn, the coloniser's Spanish fails to convey the intricacies and paradoxes of the native tongue and is eagerly contrasted with the Guarani language - a mode of expression which is equivocal ("It is a rich language wherein a single word combines both a noun and its attendant adjective, the subject and its quality"; Barker, 2017, p. 205); which contains dual, often incoherent, conflicting and contradictory meanings (Barker, 2017, pp. 218-219); and which is significantly coupled with the tongue being a form of transmedial expression: "It is only by means of music that the Paraguayans can communicate their emotions to the outside world" (Barker, 2017, p. 206). What is thus offered is a model for non-verbal and non-material communication which simultaneously makes it possible to go beyond its medium and serves as motivation for the experimental poetics of the novel. However, the effectiveness of the meaningful potential rests here on the very material dimension and on the simultaneous offering of the strategies to reaching out beyond the medium and thematising such moves in the story. This causes subsequent changes to the modes of expression used and described in the book: from the colouring of letters and words to the "fluctuation in the metal strings [Barrios] played on" (Barker, 2017, p. 219), consequently effecting a sort of veering, "special vibration" (Barker, 2017, p. 219), which contributes to the subsequent crackdown of the signifying system in the novel. Symptomatically, this is conceptualised through the graphic notation as $8 \mathrm{~Hz}$, the frequency marking the difference between the dominant Western "concert pitch" $(440 \mathrm{~Hz})$ and the more archaic "imperfect" pitch $(432 \mathrm{~Hz})$, not allowed in the over-regulated storyworld. The protagonist's recognition of the sonic difference causes disruption in the communicative layers of language and in the narrative poetics, but, importantly, it also stems from the materiality of playing the West African Kora (a harp-lute like instrument) practised by Mira. Illustrating the belief that revolutions may well have their soundtrack, this restricted and forbidden sound played by the protagonist reveals the links with the auditory domain. It enacts a form-and-content veering as conceptualised by Royle, and is noticeable in the graphic 
and verbal illustration of setting the novel's (textual) revolution in motion. The cathedral, which ultimately appears on the pages of the novel as a monument constructed from countless symbols (Barker, 2017, p. 253), is thus not only connected to a breach in the system but, through its typographical nature and its graphic construction, remains rooted in the very physicality of (graphic) art and the materiality of the novel.

The book thus sets the stage for subversion and breaches the status quo through its form, with the reader assisting in the gradual crumbling down of its means of expression. Since the novel is episodic in terms of its content, it offers gaps to fill for its readers also through the situated, first-person limited narration. Some storylines within the text remain unexplored and do not find narrative resolution, others are consumed by the graphic antics and verbal collages. Consequently, what unfolds in the process of reading tends to be laconic and in need of interpretation, providing ample material for (re)constructing the plot. Additionally, all of these practices involve a metafictional aspect: the reader reads about characters reading the Graph, and the Sensor evokes the very experience of reading itself. To follow the flow of letters in a traditional way is not only to follow the story gradually unfolding as we read on, but it is also to trace the protagonists' often insolent acts of reading when their screens display various forms of texts (correspondingly rendered in differing typefaces). Thus, while the novel depicts the metafictional experience of the procedures of reading, it does not explain the intended meaning of the graphic experiments we find on its pages. It provides an illustration of what happens when we read, while also gradually absorbing the readers into its poetics and turning them into assistants to the revolution depicted on its pages.

\section{Conclusion, or, Writing as a Performative Inscription}

The accumulation of gradually unfolding multimodal communication in Barker's novel might be read as a mark of liberation from the traditional modes of readerly experience. Elements of intense graphic interventions produce places of ambiguity, which reach out to the reader and provide visual (and other) messages one has to make sense of. H(a)ppy seems to illustrate and enact how the notion of writing, despite its permanent fixity and materiality (as print or inscription), actually relies on what might be called a performative dimension, or on it becoming an event, an experience which is rooted in the page but which grows to take place beyond its borders, in the space of literature in which the reader actively participates.

In this sense, Derrida's understanding of experience which he explored in numerous works might be helpful here. For him experience was a synonym for the genuine impossibility of repetition inherent in the literary text and in its reception. Such an approach describes the singularity contained in writing and is connected to writing which revolves around the questions of reading and giving an account of a text, or any attempts at repeating this experience. Indeed, so many of Derrida's texts illustrate, graphically or otherwise, the entanglement of language in the matters which it is used to describe: from neologisms (différance), through writing sous rature (e.g. Of Grammatology), to contrasting columns of texts together on one page (Glas), or thematically discussing the notion of borders and frames ("Living On: Borderlines"). Notably, many of these employ graphic and non-standard typographical elements which, similarly to Barker's book, suggest more complex forms of signification, but which 
also invite more dynamic acts of reading. According to Derek Attridge, these might describe elements which contribute to the actual uniqueness of the work (Singularity of Literature), not least those of defamiliarisation. Such an understanding of literature's otherness for Attridge can be expressed, for example, by "the rules and regularities that govern its forms and its operation as well as sonic, rhythmic, and graphic properties [...], more importantly, by destabilizing them, heightening their internal inconsistencies and ambiguities, exaggerating their proclivities, and exploiting their gaps and tensions" (Attridge, 2004, p. 56). The otherness of literature is thus a recognition of its uniqueness, associated with spatial arts and a certain idea of performance existing and taking place on the page and further actualised or activated in the reading process.

The problem with such an approach is that these places of ambiguity need to be properly orchestrated, i.e. pre-planned, for them to work. Barker's novel, through its fairly open construction and graphic experimentation, might suggest a similar mode of literature's singularity and testify to the continuing relevance of deconstructive methods of reading. While classical postmodern texts which employ graphic experimentation do it to parody the authority of realist fiction, works like $H($ a)ppy resort to similar strategies so they can extend the scope of their communicative effect. In the case of the novel's materiality, its veering entanglement in the theme of revolution drags the readers into its storyworld and allows them to participate in the subversive dealings of the protagonist. In destabilising its mode of expression, the text also offers an illustration of strategies for charging the materiality of writing with signification. As a result, although the readers are invited to think for themselves when faced with the nonstandard typography of the book, there is no denying that the narrative gaps and ambiguities have been orchestrated by the author and made even more effective through being coupled with notions of transgressing the limits of the medium and further emphasised by subversive content.

\section{References}

Attridge, D. (2004). The singularity of literature. London and New York: Routledge.

Barker, N. (2017). H(a)ppy. London: Penguin.

Barker, N. (2018). False starts. Granta Magazine [video interview]. Retrieved March 29, 2018, from https://www.youtube.com/watch?v=hnjZyqROHII

Barry, K. (2018). H(A)PPY. The Goldsmiths Prize. Retrieved October 10, 2018, from https://www.gold.ac.uk/goldsmiths-prize/prize2017/happy/

Barthes, R. (1977). Death of the author. In R. Barthes, Image, music, text (S. Heath, Trans.) (pp. 142-148). London: Fontana Press.

Burke, S. (1998). The death and return of the author: Criticism and subjectivity in Barthes, Foucault and Derrida. Edinburgh: Edinburgh University Press.

Byrne, E. (2020). The pursuit of happiness in $H(A) P P Y$, or what a difference an (A) makes. In B. Schoene (ed.) Nicola Barker: Critical essays. Canterbury: Gylphi [Kindle Edition], loc.34893798 . 
Darlington, J. A. (2020). Free speech and digital discourse in Nicola Barker's H(A)PPY. Lublin Studies in Modern Languages and Literature, 44(2), 99-112.

Derrida, J. (2005). Freud and the scene of writing. In J. Derrida, Writing and difference (A. Bass, Trans.) (pp. 246-291). London and New York: Routledge.

Derrida, J. (1982). Différance. In J. Derrida, Margins of philosophy (A. Bass. Trans.) (pp. 1- 27). Chicago: Harvester Press.

Foucault, M. (1984). What is an author? In P. Rabinow (Ed.), The Foucault reader (pp. 101-120). New York: Pantheon Books.

Gibbons, A. (2012). Multimodality, cognition, and experimental literature. New York and London: Routledge.

Gumbrecht, H. U. (2004). Production of presence: What meaning cannot convey. Stanford: Stanford University Press.

Hayles, N. K. (2002). Writing machines. Cambridge and London: The MIT Press.

Hutcheon, L. (2004). A poetics of postmodernism: History, theory, fiction. New York and London: Routledge.

Jordan, J. (2017, July 14). "H(a)ppy" by Nicola Barker Review - Visionary satire of a new information age. The Guardian. https://www.theguardian.com/books/2017/jul/14/happy-nicolabarker-review-science-fiction-dystopian-vision

Kress, G. \& Van Leeuwen, T. Van. (2001). Multimodal discourse: The modes and media of contemporary communication. London and New York: Arnold.

Pressman, J. (2020). Bookishness: Loving books in a digital age. New York: Columbia University Press.

Royle, N. (2011). Veering: A theory of literature. Edinburgh: Edinburgh University Press.

Sax, D. (2016). The revenge of analog: Real things and why they matter. New York: Public Affairs.

Schoene, B. (2020). The Barkeresque mode: An introduction. In B. Schoene (ed.) Nicola Barker: Critical essays. Canterbury: Gylphi [Kindle Edition], loc.95-433.

Tymon Adamczewski is assistant professor at the Department of Anglophone Literatures of Kazimierz Wielki University in Bydgoszcz, Poland, where he teaches literary and cultural studies. He is the author of Following the Textual Revolution: The Standardization of Radical Critical Theories of the 1960s (McFarland 2016) and has published articles (in AVANT, Image [\&] Narrative, NJES, Theoretical Practice, among others) which address diverse aspects of critical theories in various contexts. He has recently edited a monograph entitled All Along Bob Dylan: America and the World (Routledge 2020) and is interested in the critical discourses of contemporary humanities, music and ecocriticism. 